\title{
RELATIONSHIP BETWEEN DAILY PHYSICAL ACTIVITY LEVEL AND LOW BACK PAIN IN YOUNG, FEMALE DESK-JOB WORKERS
}

\section{GURHAN KAYIHAN}

Personal Nutrition Training Center, Ankara, Turkey

Physical Fitness Department

\begin{abstract}
Objectives: The purpose of this study was to investigate the relationship between daily physical activity (PA) level and low back pain (LBP) in young women. Material and Methods: Two hundred forty three female, desk-job workers aged 20-40 voluntarily participated in the study. The participants were assessed by the use of Oswestry Disability Index for measuring LBP disability and by the use of the short version of the International Physical Activity Questionnaire for PA assessment. The 1-way ANOVA test was used for comparing the mean values according to the physical activity level groups. Correlations between the average LBP disability score and all the other variables were obtained using Pearson's correlation analysis. The level of statistical significance was $p<0.05$. Results: Significant differences were found for LBP disability score between the results of 3 different PA groups $(\mathrm{p}<0.05)$ (low, moderate and high PA groups). The correlation between the average LBP disability score and body weight ( $\mathrm{r}=0.187$, $\mathrm{p}<0.01)$, body mass index $(\mathrm{r}=0.165, \mathrm{p}<0.01)$, vigorous MET score $(\mathrm{r}=0.247, \mathrm{p}<0.01)$ and total PA MET score $(r=0.131, p<0.01)$ were significant. Conclusions: The main finding of this study is that there is a U-shaped relationship between PA and LBP disability score in young women. A moderate level of daily physical activity and preventing body weight and fat gain should be recommended in young, female desk-job workers in order to prevent and manage low back pain.
\end{abstract}

Key words:

Sedentary lifestyle, Physical activity, Back pain, Women, Workers

\section{INTRODUCTION}

Low back pain (LBP) is defined as "any back pain between the ribs and the top of the leg, from any reason" [1,2]. According to Ehrlich, "LBP is neither a disease nor a diagnostic entity of any sort" [3]. LBP is one of the most common problems in adults. The most recent reviews of the prevalence of LBP have shown that the point prevalence rate was estimated to be between $12-33 \%[1,4]$. Physical activity (PA) is typically defined as "any bodily movement produced by skeletal muscles that results in energy expenditure beyond resting expenditure" [5].

Public health guidelines recommend regular PA to minimize the risk of chronic diseases [5-7]. Previous studies have demonstrated that there is a U-shaped relationship between LBP and PA [8,9]. These studies showed that sedentary lifestyle and strenuous levels of PA are more associated with LBP than moderately intense PA [10-12]. Sedentary workers who sit for a long period have a higher risk of diabetes, cardiovascular diseases as well as

Received: January 31, 2014. Accepted: July 1, 2014.

Corresponding author: G. Kayihan, Lea Grove, Didcot, Oxfordshire, OX11 7UN, UK (e-mail: gkayihan@yahoo.com). 
cardiovascular and all-cause mortality [13-15]. Despite these citations and their widespread acceptance, there have been few published articles [8,16] showing the relationship between LBP and daily PA levels in female deskjob workers. Scientific evidence of the role of daily PA in prevention and management of LBP was lacking in the case of young, female workers. It is hypothesized that maintaining moderate levels of daily PA will be associated with fewer LBP complaints. The purpose of this study was to investigate the relationship between daily PA levels and LBP in young, female desk-job workers aged 20-40.

\section{MATERIAL AND METHODS}

\section{Participants and test procedures}

The present study is based on the survey data collected among female workers who booked doctor appointments for a physical examination such as routine regular medication reviews and made blood test requests. Two hundred forty three female, desk-job workers within the age range of 20-40 years participated in this study voluntarily. Their mean age was $29.20 \pm 5.91$ years, height $-1.63 \pm 0.05 \mathrm{~m}$, body weight $-63.83 \pm 7.63 \mathrm{~kg}$ and body mass index (BMI) $-23.91 \pm 3.11$.

\section{Body composition assessment}

Body height and weight were measured at the assessment day. Body weight of the participants in minimal clothing (underwear) was measured to the nearest $100 \mathrm{~g}$ with a precision scale and the body height was measured to the nearest $5 \mathrm{~mm}$ with a Holtain stadiometer [17]. Body mass index was calculated using the formula: weight $(\mathrm{kg})$ divided by height (m) squared.

\section{Physical activity level assessment}

Physical activity was assessed using the short version of The International Physical Activity Questionnaire (IPAQ) and scored according to the method of Craig et al. [18].
The questionnaire was developed as an instrument for cross-national monitoring of physical activity and inactivity. The questionnaire was designed to be used by adults aged 18-65 years.

The short version of the questionnaire (9 items) provides information on the time spent walking, doing vigorous to moderate intensity physical activity and sedentary activity. The participants were instructed to refer to all the areas of physical activity. Data from the short IPAQ questionnaires were summarized according to the physical activities recorded (walking, moderate, and vigorous activities). Data from the questionnaires were used to estimate the total weekly physical activity by weighting the reported minutes per week within each activity category according to the metabolic equivalent of task (MET) - energy expenditure estimate assigned to each category of activity.

$$
\begin{gathered}
\text { Walking MET-min/week }=3.3 \times \text { walking time }(\min ) \times \\
\text { walking days } \\
\text { Moderate MET-min/week }=4 \times \\
\text { moderate-intensity activity time }(\mathrm{min}) \times \\
\text { moderate days } \\
\text { Vigorous MET-min/week }=8 \times \\
\text { vigorous-intensity activity time }(\mathrm{min}) \times \\
\text { vigorous-intensity days } \\
\text { Total physical activity MET-min/week }= \\
\text { sum of walking + moderate }+ \text { vigorous }
\end{gathered}
$$

If the participants met at least 1 of the criteria below they were classified as 'moderate':

- 3 or more days of vigorous-intensity activity of at least $20 \mathrm{~min} /$ day,

- 5 or more days of moderate-intensity activity and/or walking of at least $30 \mathrm{~min} /$ day,

- 5 or more days of any combination of walking, moderate-intensity or vigorous intensity activities achieving a minimum total physical activity of at least 600 MET-min/week.

If the participants met at least 1 of the criteria cited below they were classified as 'high': 
- vigorous-intensity activity on at least 3 days achieving a minimum total physical activity of at least 1500 MET-min/week,

- 7 or more days of any combination of walking, moderate-intensity or vigorous-intensity activities achieving a minimum total physical activity of at least 3000 MET-min/week.

The participants who did not meet criteria for moderate or high categories were considered to have a 'low' physical activity level.

\section{Low back pain assessment}

The participants were assessed by the use of the Turkish version of the Oswestry Disability Index for measuring disability. The Oswestry Disability Index is one of the most commonly used and validated scales for measuring disability for people with LBP. The questionnaire consists of 10 items addressing different aspects of function. Each item is scored from 0 to 5, with higher values representing greater disability. The total score is multiplied by 2 and expressed as a percentage [19,20].

\section{ETHICS}

The participants signed an informed consent before commencement of the study and the author confirms that this study meets the guidelines of the Helsinki Declaration.

\section{STATISTICS}

Means and standard deviations are given as descriptive statistics. The One-way ANOVA test was used for comparing the mean values according to the 3 different physical activity level groups. The Tukey post hoc test was used to follow-up with the group factor. Correlations between the average LBP disability score and all the other variables were obtained using Pearson's correlation analysis. For all statistics the significance level was set at $\mathrm{p}<0.05$.
The data were analysed using the Statistical Package for Social Sciences (SPSS) MS Windows Release 17.0.

\section{RESULTS}

There are no significant differences for age, body weight, body height and BMI between the 3 physical activity groups. However, significant differences were found for LBP disability score between the results of the 3 physical activity groups $(\mathrm{p}<0.05)$ (Figure 1$)$. LBP disability score in the moderate physical activity group was significantly lower $(\mathrm{p}<0.05)$ than in the low and high physical activity groups. There is no significant difference for LBP disability score between the low and high physical activity groups (Table 1).

Although, the correlation coefficient between the average LBP disability score and body weight $(\mathrm{r}=0.187$, $\mathrm{p}<0.01)$, body mass index $(\mathrm{r}=0.165, \mathrm{p}<0.01)$, vigorous MET score $(r=0.247, p<0.01)$ and total physical activity MET score $(r=0.131, \mathrm{p}<0.01)$ were significant, there is no significant relationship between the LBP disability score and age, body height, Moderate MET score and Walking MET score $(\mathrm{p}>0.05)$ (Table 2).

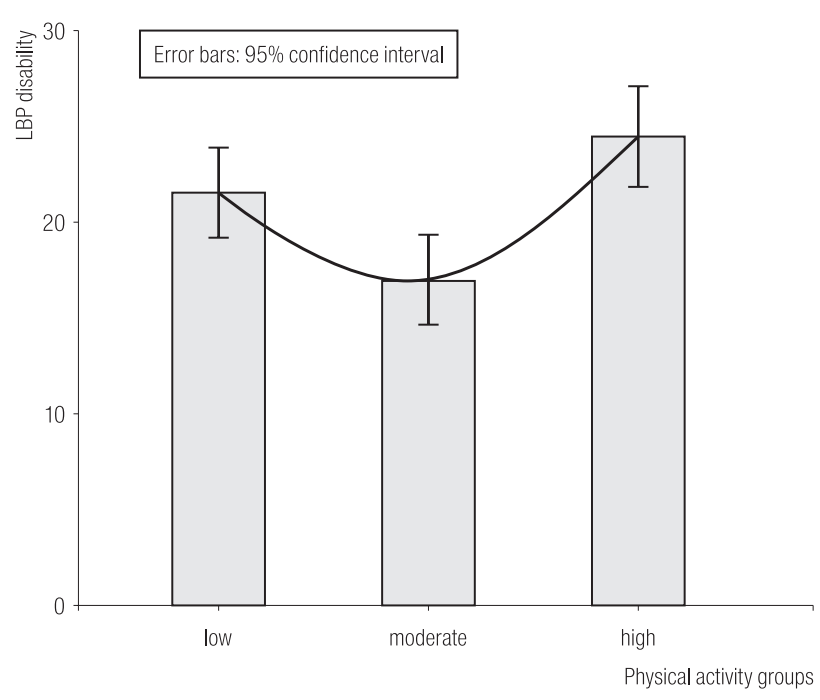

Fig. 1. Low back pain (LBP) disability score in the study groups 
Table 1. The means (M) and standard deviations (SD) of all dependent variables according to the physical activity groups

\begin{tabular}{|c|c|c|c|c|c|c|c|c|c|c|}
\hline \multirow[b]{2}{*}{ Variable } & \multicolumn{3}{|c|}{$\begin{array}{l}\text { Physical activity } \\
(\mathrm{M} \pm \mathrm{SD})\end{array}$} & \multicolumn{2}{|c|}{$\begin{array}{c}\mathrm{L}-\mathrm{M} \\
\text { difference }\end{array}$} & \multicolumn{2}{|c|}{$\begin{array}{c}\mathrm{L}-\mathrm{H} \\
\text { difference }\end{array}$} & \multicolumn{2}{|c|}{$\begin{array}{c}\mathrm{M}-\mathrm{H} \\
\text { difference } \\
\end{array}$} & \multirow[b]{2}{*}{$\mathrm{p}^{2}$} \\
\hline & $\begin{array}{c}\text { low } \\
(\mathrm{L}) \\
(\mathrm{N}=88)\end{array}$ & $\begin{array}{c}\text { moderate } \\
(\mathrm{M}) \\
(\mathrm{N}=81)\end{array}$ & $\begin{array}{c}\text { high } \\
(\mathrm{H}) \\
(\mathrm{N}=74)\end{array}$ & $\mathrm{M} \pm \mathrm{SD}$ & $\mathrm{p}^{1}$ & $\mathrm{M} \pm \mathrm{SD}$ & $\mathrm{p}^{1}$ & $\mathrm{M} \pm \mathrm{SD}$ & $\mathrm{p}^{1}$ & \\
\hline Age (years) & $30.03 \pm 5.92$ & $28.78 \pm 5.32$ & $28.66 \pm 6.47$ & $1.26 \pm 0.91$ & ns. & $1.37 \pm 0.93$ & ns. & $0.12 \pm 0.95$ & ns. & ns. \\
\hline Body weight (kg) & $64.70 \pm 6.71$ & $62.87 \pm 7.59$ & $63.84 \pm 8.60$ & $1.83 \pm 1.18$ & ns. & $0.87 \pm 1.20$ & ns. & $-0.97 \pm 1.23$ & ns. & ns. \\
\hline Body height (cm) & $163.65 \pm 5.53$ & $164.19 \pm 5.39$ & $162.76 \pm 5.83$ & $-0.54 \pm 0.86$ & ns. & $0.89 \pm 0.88$ & ns. & $1.43 \pm 0.90$ & ns. & ns. \\
\hline Body mass index & $24.19 \pm 2.63$ & $23.36 \pm 3.01$ & $24.18 \pm 3.67$ & $0.83 \pm 0.48$ & ns. & $-0.01 \pm 0.49$ & ns. & $-0.82 \pm 0.50$ & ns. & ns. \\
\hline LBP disability & $21.59 \pm 11.04$ & $17.04 \pm 10.76$ & $24.54 \pm 11.50$ & $4.55 \pm 1.70$ & 0.022 & $-2.95 \pm 1.75$ & ns. & $-7.50 \pm 1.78$ & 0.000 & 0.000 \\
\hline
\end{tabular}

LBP - low back pain.

$\mathrm{p}<0.05$.

${ }^{1}$ According to post hoc multiple comparisons.

${ }^{2}$ Comparison among 3 approaches (One-Way ANOVA).

ns. - not statistically significant.

Table 2. Correlations (P-Pearson) between the variables in the study groups

\begin{tabular}{lcccccccc}
\hline \multicolumn{1}{c}{ Variable } & \multicolumn{7}{c}{ P-Pearson correlation } \\
\cline { 2 - 9 } & 1 & 2 & 3 & 4 & 5 & 6 & 7 & 8 \\
\hline 1. LBP disability & - & - & - & - & - & - & - & - \\
2. Age (years) & -0.022 & - & - & - & - & - & - & - \\
3. Body weight (kg) & $0.187^{* *}$ & $0.256^{* *}$ & - & - & - & - & - & - \\
4. Body height (cm) & 0.030 & $-0.248^{* *}$ & $0.163^{*}$ & - & - & - & - & - \\
5. Body mass index & $0.165^{* *}$ & $0.382^{* *}$ & $0.849^{* *}$ & $-0.379^{* *}$ & - & - & - & - \\
6. Vigorous MET & $0.247^{* *}$ & -0.045 & 0.010 & $-0.127^{*}$ & 0.078 & - & - & - \\
7. Moderate MET & -0.034 & $-0.131^{*}$ & 0.036 & -0.070 & 0.073 & 0.076 & - & - \\
8. Walking MET & 0.098 & $-0.131^{*}$ & $-0.143^{*}$ & 0.075 & $-0.172^{* *}$ & 0.099 & 0.015 & - \\
9. Total physical activity MET & $0.131^{*}$ & -0.014 & -0.025 & -0.101 & 0.033 & $0.803^{* *}$ & $0.545^{* *}$ & $0.427^{* *}$ \\
\hline
\end{tabular}

LBP - low back pain; MET - metabolic equivalent of task.

${ }^{* *} \mathrm{p}<0.01 ;{ }^{*} \mathrm{p}<0.05$.

\section{DISCUSSION}

In general, the results of this study have supported the hypothesis mentioned in the 'Introduction' part. This study shows that both low and high daily physical activity levels are associated with a higher LBP disability score. The study results concerning the relationship between LBP and physical activity level support previous studies and suggest that moderate levels of physical activity are associated with a lower risk of LBP. Similarly to previous studies, the current study shows that the relationship between the level of activity and LBP disability follows a U-shaped curve in young, female desk-job workers [21-24].

The previous studies have demonstrated that vigorous physical activity and workloads are hazardous for the lower back. Vigorous physical activity and strenuous workload are risk factors for LBP [16,21-24]. Bihari et al. [16] and 
Kar et al. [25] have shown that women with heavy work loads had more musculoskeletal pain than others. Furthermore, Burdorf et al. [26] have found that sedentary workers who have to work in non-neutral positions are more at risk of LBP. Pataro and Fernandes (2014) state that LBP was associated with longer working hours, flexion and trunk rotation. Dynamic activity such as walking or running served as a protective factor [27]. Moreover, Caban et al. (2014) found that the percentage of workers with ankle and knee pain was significantly higher among workers who join regular moderate and vigorous PA programs than among those who do not attend such programs [28]. Similarly, in this research it was found that there was a significant relationship between the LBP disability score and vigorous MET score $(r=0.247, p<0.01)$. This relationship was higher than the total physical activity MET score $(\mathrm{r}=0.131, \mathrm{p}<0.01)$. Moreover, in this study, while the moderate physical activity level group's LBP disability score amounted to $17.04 \pm 10.76$, the LBP disability score in the high physical activity level group was $24.54 \pm 11.50$. Comparing to the moderate physical activity level group, the LBP disability scores in the low physical activity level group increased to $21.59 \pm 11.04$.

Han et al. (1997) found that overweight women have a significantly increased likelihood of LBP and no significant interaction between body mass index and low back pain symptoms was found [29]. On the other hand, some studies have shown a statistically significant but weak positive association between body weight and LBP. Increased mechanical demands resulting from a higher body weight have been suspected of causing LBP [24,30-33]. Similarly, this study supports that body weight and BMI should be accepted as weak risk signals for LBP due to lower relations.

There are several limitations of this study. Both the intake data for the physical activity level and LBP disability scores are self-reported. The participants might have been confused by the complex questionnaire using terms which are often unfamiliar for them such as "moderate," "vigorous," etc., and self-report methods generally provide poor estimates of physical activity [34,35]. However, self-reports used in this study have been shown to be valid in the case of assessments of the physical activity level $[18,36,37]$. The short version of the IPAQ, especially, has been used in numerous international studies [38]. As previously noted, the Oswestry Disability Index is one of the most commonly used and validated scales and this index is simple, quick and inexpensive. Despite the advantages of self-reported methods for LBP disability, this questionnaire is subjective and there is no absolute measure of disability due to pain. Again, the participants may be confused by the double-barrelled questions [20]. The main strength of this study is the large size of the cohort and it is the 1st study to investigate the relationship between daily PA levels and LBP in young, female desk-job workers aged 20 to 40.

\section{CONCLUSIONS}

The main finding of this study is that there is a U-shaped relationship between physical activity and LBP disability score in young, female desk-job workers. In the case of young, female desk-job workers a moderate level of daily physical activity, and preventing body weight and fat gain should be recommended for prevention and management of low back pain. Increases in exercise training enhance skeletal muscle mass and decrease musculoskeletal pain [7]. Because of this, young, female desk-job workers should perform the levels of physical activity recommended by the World Health Organization, which is at least 150 min of moderate-intensity aerobic physical activity throughout the week or at least 75 min of vigorousintensity aerobic physical activity throughout the week, or an equivalent combination of moderate and vigorous-intensity activity [7]. In addition, those women should avoid vigorous physical activity which may cause back muscle strains or ligament strains, such as: lifting heavy objects, twisting or sudden movements [10,21,22,26]. 


\section{ACKNOWLEDGEMENTS}

The author would like to extend his thanks to Dr. Melanie Smith for her help with language editing of this manuscript.

\section{REFERENCES}

1. Loney PL, Stratford PW. The prevalence of low back pain in adults: A methodological review of the literature. Phys Ther. 1999;79(4):384-96.

2. Frank JW, Kerr MS, Brooker A-S, DeMaio SE, Maetzel A, Shannon HS, et al. Disability resulting from occupational low back pain: Part I: What do we know about primary prevention? A review of the scientific evidence on prevention before disability begins. Spine. 1996;21(24):2908-17, http://dx.doi.org/ 10.1097/00007632-199612150-00024.

3. Ehrlich GE. Low back pain. Bull World Health Organ. 2003;81(9):671-6.

4. Walker BF. The prevalence of low back pain: A systematic review of the literature from 1966 to 1998. J Spinal Disord. 2000;13(3):205-17, http://dx.doi.org/10.1097/00002517200006000-00003.

5. Pate RR, Pratt M, Blair SN, Haskell WL, Macera CA, Bouchard C, et al. Physical activity and public health. JAMA. 1995;273(5):402-7， http://dx.doi.org/10.1001/jama. 1995.03520290054029.

6. U.S. Department of Health and Human Services. Physical activity and health: A report of the Surgeon General. Washington: DIANE Publishing; 1996.

7. U.S. Department of Health and Human Services. 2008 physical activity guidelines for Americans. Be active, healthy, and happy. Washington: USDHHS; 2008.

8. Heneweer H, Vanhees L, Picavet HSJ. Physical activity and low back pain: A U-shaped relation? Pain. 2009;143(1):21-5, http://dx.doi.org/10.1016/j.pain.2008.12.033.

9. Heneweer H, Staes F, Aufdemkampe G, van Rijn M, Vanhees L. Physical activity and low back pain: A systematic review of recent literature. Eur Spine J. 2011;20(6):826-45, http://dx.doi.org/10.1007/s00586-010-1680-7.
10. Hoogendoorn WE, van Poppel MN, Bongers PM, Koes BW, Bouter LM. Physical load during work and leisure time as risk factors for back pain. Scand J Work Environ Health. 1999;25(5):387-403, http://dx.doi.org/10.5271/sjweh.451.

11. Jacob T, Baras M, Zeev A, Epstein L. Physical activities and low back pain: A community-based study. Med Sci Sports Exerc. 2004;36(1):9-15, http://dx.doi.org/10.1249/01. MSS.0000106166.94343.02.

12. Kujala UM, Taimela S, Viljanen T. Leisure physical activity and various pain symptoms among adolescents. Br J Sports Med. 1999;33(5):325-8, http://dx.doi.org/10. 1136/bjsm.33.5.325.

13. Wilmot E, Edwardson C, Achana F, Davies M, Gorely T, Gray L, et al. Sedentary time in adults and the association with diabetes, cardiovascular disease and death: Systematic review and meta-analysis. Diabetologia. 2012;55(11): 2895-905, http://dx.doi.org/10.1007/s00125-012-2677-z.

14. Morris J, Heady J, Raffle P, Roberts C, Parks J. Coronary heart-disease and physical activity of work. Lancet. 1953;262(6796):1111-20, http://dx.doi.org/10.1016/S0140-67 36(53)91495-0.

15. van Uffelen JG, Wong J, Chau JY, van der Ploeg HP, Riphagen I, Gilson ND, et al. Occupational sitting and health risks: A systematic review. Am J Prev Med. 2010;39(4): 379-88, http://dx.doi.org/10.1016/j.amepre.2010.05.024.

16. Bihari V, Kesavachandran C, Pangtey B, Srivastava A, Mathur N. Musculoskeletal pain and its associated risk factors in residents of National Capital Region. Indian J Occup Environ Med. 2011;15(2):59, http://dx.doi.org/10.4103/ 0019-5278.90375.

17. Gordon C, Chumlea W, Roche A. Stature, recumbent length, and weight. In: Lohman T, Roche A, Martorell R, editors. Anthropometric standardization reference manual. Champaign: Human Kinetics Books; 1988. p. 3-8.

18. Craig C, Marshall A, Sjöström M, Bauman A, Booth M, Ainsworth B, et al. The IPAQ reliability and validity study group. International Physical Activity Questionnaire (IPAQ): 12-country reliability and validity. Med Sci Sports 
Exerc. 2003;35:1381-95, http://dx.doi.org/10.1249/01.MSS. 0000078924.61453.FB.

19. Yakut E, Düger T, Öksüz Ç, Yörükan S, Üreten K, Turan D, et al. Validation of the Turkish version of the Oswestry Disability Index for patients with low back pain. Spine. 2004;29(5):581-5, http://dx.doi.org/10.1097/01.BRS. 0000113869.13209.03.

20. Fairbank J, Couper J, Davies J, O'brien J. The Oswestry low back pain disability questionnaire. Physiotherapy. 1980;66(8):271-3.

21. Hoogendoorn W, Bongers P, de Vet H, Ariens G, van Mechelen W, Bouter L. High physical work load and low job satisfaction increase the risk of sickness absence due to low back pain: Results of a prospective cohort study. Occup Environ Med. 2002;59(5):323-8, http://dx.doi.org/ 10.1136/oem.59.5.323.

22. Kopec JA, Sayre EC, Esdaile JM. Predictors of back pain in a general population cohort. Spine. 2004;29(1):70-7, http://dx.doi.org/10.1097/01.BRS.0000103942.81227.7F.

23. Miranda H, Viikari-Juntura E, Martikainen R, Takala EP, Riihimäki H. Individual factors, occupational loading, and physical exercise as predictors of sciatic pain. Spine. 2002;27(10):1102-8, http://dx.doi.org/10 . 1097/00007632-200205150-00017.

24. Chaffin DB, Park KS. A longitudinal study of low-back pain as associated with occupational weight lifting factors. Am Ind Hyg Assoc J. 1973;34(12):513-25, http://dx.doi.org/ 10.1080/0002889738506892.

25. Kar S, Dhara P. An evaluation of musculoskeletal disorder and socioeconomic status of farmers in West Bangal, India. Nepal Med Coll J. 2007;9(4):245-9.

26. Burdorf A, Naaktgeboren B, de Groot HC. Occupational risk factors for low back pain among sedentary workers. J Occup Med. 1993;35(12):1213-20.

27. Pataro S, Fernandes R. Heavy physical work and low back pain: The reality in urban cleaning. Rev Bras Epidemiol. 2014;17(1):17-30, http://dx.doi.org/10.1590/1415-790X 201400010003ENG.
28. Caban A, Lowe K, Herrick R, Kenwood C, Gagne J, Backer J. Construction workers working in musculoskeletal pain and engaging in leisure-time physical activity: Findings from a mixed-methods pilot study. Am J Ind Med. 2014;57(7): 819-25, http://dx.doi.org/10.1002/ajim.22332.

29. Han T, Schouten J, Lean M, Seidell J. The prevalence of low back pain and associations with body fatness, fat distribution and height. Int J Obesity. 1997;21(7):600-7, http:/ dx.doi.org/10.1038/sj.ijo.0800448.

30. Leboeuf-Yde C. Body weight and low back pain: A systematic literature review of 56 journal articles reporting on 65 epidemiologic studies. Spine. 2000;25(2):226, http:// dx.doi.org/10.1097/00007632-200001150-00015.

31. Böstman O. Body mass index and height in patients requiring surgery for lumbar intervertebral disc herniation. Spine. 1993;18(7):851-4, http://dx.doi.org/10.1097/00007632199306000-00007.

32. Wright D, Barrow S, Fisher A, Horsley S, Jayson M. Influence of physical, psychological and behavioural factors on consultations for back pain. Rheumatology. 1995;34(2): 156-61, http://dx.doi.org/10.1093/rheumatology/34.2.156.

33. Hultman G, Nordin M, Saraste H, Ohlsèn H. Body composition, endurance, strength, cross-sectional area, and density of MM erector spinae in men with and without low back pain. J Spinal Disord. 1993;6(2):114-23, http://dx.doi.org/ 10.1097/00024720-199304000-00004.

34. Sallis JF, Saelens BE. Assessment of physical activity by self-report: Status, limitations, and future directions. Res Q Exerc Sport. 2000;71(2 Suppl):S1-14.

35. Schuna JM, Johnson WD, Tudor-Locke C. Adult self-reported and objectively monitored physical activity and sedentary behavior: NHANES 2005-2006. Int J Behav Nutr Phys Act. 2013;10:126, http://dx.doi.org/10.1186/1479-5868-10-126.

36. Saglam M, Arikan H, Savci S, Inal-Ince D, Bosnak-Guclu M, Karabulut E, et al. International physical activity questionnaire: Reliability and validity of the Turkish version. Percept Motor Skill. 2010;111(1):278-84, http://dx.doi. org/10.2466/06.08.PMS.111.4.278-284. 
37. Booth ML, Ainsworth BE, Pratt M, Ekelund U, Yngve A, Sallis JF, et al. International physical activity questionnaire: 12-country reliability and validity. Med Sci Sports Exerc. 2003;35(8):1381-95, http://dx.doi.org/10.1249/01. MSS.0000078924.61453.FB.
38. Hagströmer M, Oja P, Sjöström M. The International Physical Activity Questionnaire (IPAQ): A study of concurrent and construct validity. Public Health Nutr. 2006;9(6): 755-62, http://dx.doi.org/10.1079/PHN2005898.

This work is available in Open Access model and licensed under a Creative Commons Attribution-NonCommercial 3.0 Poland License - http://creativecommons.org/ licenses/by-nc/3.0/pl/deed.en. 